\title{
Knowledge, Attitude, Behavior Men Who Have Sex with Men Related to HIV/AIDS in Semarang Indonesia
}

\section{Puguh Riyanto*}

Faculty of Medicine, Diponegoro University/Kariadi Hospital, Semarang, Indonesia

\begin{abstract}
Background: Across the Asian continent, the issue of sexual behavior of men who have sex with men (MSM) has become a subject of significant interest in human immunodeficiency virus infection (HIV) Infections among the MSM population. This study aims to see how knowledge, attitude, behavior of MSM with HIVIAIDS.

Results: Age of respondents from 17 to 40 years gay $45.9 \%$, bisexual $24.7 \%$, heterosexual $25 \%$. The majority of MSM have heard of HIV / AIDS, know about HIV, anal sex, the use of needle-sharing syringes are at risk of transmitting HIV, and social relationships can not transmit HIV. MSM often had anal sex of $50 \%$, not frequent anal sex $34.3 \%$. Always use a condom $24.3 \%$, sometimes using a condom $27.1 \%$, and not at all wearing a condom $48.6 \%$. MSM who had tested HIV $32.9 \%$, was never tested $61.4 \%$.
\end{abstract}

Conclusions: Knowledge, attitudes, and behavior of MSM are particularly at risk for contracting HIV.

Keywords: Knowledge; Attitude; Behavior; MSM; HIV

\section{Introduction}

Across the Asian continent, the issue of sexual behavior of men who have sex with men (MSM) has become a subject of significant interest in human immunodeficiency virus infection (HIV) Infections among the MSM population. MSM are now considered one of the main target groups for HIV prevention programs. In 2009, the World Health Organization found that the prevalence of HIV was falling, while the prevalence of HIV among the MSM population continues to rise, particularly in certain parts of Asia. The epidemic situation of HIV and AIDS in the world until the end of 2020 will continue to increase in prevalence, still concentrated in the most at risk populations. This study aims to see how knowledge, attitude, behavior of MSM with HIV /AIDS in Semarang, Indonesia.

\section{Methods}

This research was conducted in August 2016 in Semarang City, Central Java, Indonesia. The data collection in this research is done through focus group discussion (FGD), semi structured interview, observation, child history, social support networking. The population of this study is MSM in Semarang City. The validity of data using source triangulation by confirmation from several sources that are still related to this research problem are Health Service Office in Central Java Province, AIDS Prevention Commission, Puskesmas or Hospital providing STI service and VCT test, non-governmental organizations and volunteers in Semarang. Data on the characteristics, knowledge, attitudes and behavior of HIV/AIDS-related MSM are presented descriptively.

\section{Results}

Respondents in this study were 85 people from North Semarang, West Semarang, East Semarang, Central Semarang, South Semarang, Mangkang, Gajah Mungkur and Banyumanik. Generally MSM in Semarang often gather, get acquainted, dating with fellow MSM. They often meet in other places such as swimming pools, markets, mosques, cafes, discotheques and malls. MSM's favorite place in Semarang is in the park around Tugu Muda, Simpang Lima, Mentri Supeno Park, Pandanaran Park, Sampangan Park, Tirto Agung Tembalang Park, Telogosari Virgin Park, Terboyo Station, Mangkang Station, Penggaron
Station, Sukun Station, market birds Karimata, Johar Market, Jatingaleh Market, Jati diri Sports Hall, Manungggal Jati Arena, Citraland Mall, Paragon Mall, Ada Supermarket, car free day event on Pahlawan and Pemuda roads.

Age of respondents in this study the youngest 17 years, while the oldest is 40 years. Their recognition identity as gay $45.9 \%$, bisexual $24.7 \%$, heterosexual $25 \%$. Education majority of high school students or equal to $37.6 \%$ and college graduates is $23.5 \%$. The occupation of the respondents as sex workers was only $5.9 \%$, they were mostly unmarried, and those who consumed drugs were only $3.5 \%$ (Table 1 ).

Respondents' knowledge of HIV, as many as $98.2 \%$ of respondents said they had heard of HIV and AIDS disease and $1.8 \%$ of respondents said they had never heard of HIV and AIDS. Respondents, who know HIV transmission through anal sex $91.2 \%$, while those who do not know $8.8 \%$. Transmission of HIV from syringes used together with respondents who know $96.4 \%$, while those who do not know $3.6 \%$. Knowledge of social relationships does not transmit HIV like a handshake, using clothing and cutlery with respondents who know $90.8 \%$, while those who do not know 9.2\%. Respondents stated that people can not get HIV from mosquito bites $85 \%$, while $15 \%$ say that people can get HIV from mosquito bites. Knowledge about condom use can reduce the risk of contracting HIV, the majority of respondents said people can reduce the risk of contracting HIV by using condoms properly every $95.6 \%$ of anal sex, while $4.4 \%$ say no. Knowledge of faithful sex partners can avoid HIV transmission, obtained some $85.3 \%$ of respondents agreed and $14.7 \%$ disagree.

*Corresponding author: Dr. Puguh Riyanto, M.D., D.V., Department of Dermatology and Venereology, Faculty of Medicine, Diponegoro University/Kariadi Hospital; dr.Soetomo street 18 Semarang city, central java, Indonesia; Tel: +62 856-4154-5698; E-mail : Puguhungaran@gmail.com

Received April 25, 2017; Accepted May 16, 2017; Published May 23, 2017

Citation: Riyanto P (2017) Knowledge, Attitude, Behavior Men Who Have Sex with Men Related to HIVIAIDS in Semarang Indonesia. J AIDS Clin Res 8: 693. doi: 10.4172/2155-6113.1000693

Copyright: (C) 2017 Riyanto P. This is an open-access article distributed under the terms of the Creative Commons Attribution License, which permits unrestricted use, distribution, and reproduction in any medium, provided the original author and source are credited. 


\begin{tabular}{|l|c|c|}
\hline Variable & Frequency & $\%$ \\
\hline \begin{tabular}{l|c|} 
Age (year) \\
Mean \pm SD
\end{tabular} & 22.23 .2 & \\
\hline Identity & & \\
\hline Gay & 39 & 24.9 \\
\hline Bisexual & 21 & 29.4 \\
\hline heterosexual & 25 & 23.5 \\
\hline Education & & 37.6 \\
\hline University & 20 & 18.8 \\
\hline Senior high school & 32 & 2.4 \\
\hline Junior high school & 16 & 17.7 \\
\hline Primary school & 2 & \\
\hline Etc. & 15 & 2.4 \\
\hline Occupation & & 27.1 \\
\hline Government employees & 2 & 35.2 \\
\hline Entrepreneur & 23 & 5.9 \\
\hline Labor & 30 & 29.4 \\
\hline Male sex worker & 5 & 23.5 \\
\hline Etc. & 25 & 70.6 \\
\hline Marital status & & 5.9 \\
\hline Married & 20 & 3.5 \\
\hline Unmarried & 60 & 96.5 \\
\hline Widower & 5 & \\
\hline Use drugs & & \\
\hline Yes & 32 & \\
\hline No & & \\
\hline & & \\
\hline
\end{tabular}

Table 1: Characteristics of study respondents by age, identity, education, occupation, marital status and taking drugs in the MSM community in Semarang City Indonesia, in August 2016, with a sample size of 85 people.

Attitudes and behavior of MSM to anal intercourse are at high risk of contracting HIV, some $50 \%$ of respondents said they often have anal sex, while $34.3 \%$ say they do not have anal sex and $27.9 \%$ do not know. Attitudes and behavior of MSM in the use of condoms during sex activities, which uses condoms $3.3 \%$, while those who do not use condoms obtained 93.6\%. MSM reasons not use condoms during sexual intercourse, among others because of $20 \%$ antibiotic injection; the sexual partner is clean not sick $80 \%$.

MSM attitudes and behavior of HIV testing and counseling, respondents said know the test site to find themselves infected with HIV or not a number of $62.1 \%$, while MSM who do not know $37.9 \%$. Respondents claimed to have had a $32.9 \%$ HIV test, while not claiming to have tested $67.1 \%$. Respondents stated that they tested their own willingness of $30.7 \%$, while $61.4 \%$ did not test their own volition, and $7.9 \%$ did not know. Respondents said they knew the test result was $31.4 \%$, while $60.7 \%$ said they did not know the test result. And $7.9 \%$ did not answer. Respondents stated that they had received counseling when they took HIV test of $32.9 \%$, while $67.1 \%$ did not respond. A total of $28.6 \%$ of respondents stated that they routinely conducted HIV testing, while $62.9 \%$ said they did not regularly test HIV and $7.8 \%$ did not know.

\section{Discussion}

The characteristics of MSM in this study are not much different from those of South African, English, Chinese, Hong Kong and US cities [1-7]. Male sex-related men meant to explain all men who have sex with men, regardless of their sexual identity, it is only a small number of men engaged in same-sex sexual behavior defined as gay, homosexual and bisexual but more accurately identifying themselves

using local social and sexual identity and behavior. They do not consider their sexual relationships with other men in identity terminology or sexual orientation. Many who have sex with men identify themselves as heterosexuals instead of homosexual or bisexual, especially if they also have sex with women, marry, only play the role of penetrative parties in anal sex or have sex with men for money or pleasure $[1,3]$.

The majority of the MSM community who became respondents in this study had heard about HIV and AIDS, knowing anal sex is at risk of contracting HIV, the use of a syringe that alternately can transmit HIV. Social relationships can not transmit HIV. The knowledge that condom use and a faithful partner can reduce HIV transmission is not much different from studies in South Africa, China and the United States $[1,2,8]$. The majority of MSM in this study have anal sex. The majority of MSM in this study did not use condoms when having sex for various reasons, such as feeling they were not infected with HIV, always injecting antibiotics, sex sniffing, this is different from research in western countries that use condoms during anal sex. Anal sex behavior in MSM who do not use condoms is a risk of contracting HIV [1]. The majority of MSM in the study never conducted HIV counseling and testing, indicating that in general MSM communities are afraid to test for VCT for various reasons, such as fear of knowing the outcome, time $[1,3]$

Descriptions of knowledge, attitudes and sexual behavior of MSM in relation to HIV and AIDS are enough to justify the need to establish healthy sexual attitudes and behaviors among MSM. As it is known that MSM communities are vulnerable to AIDS. With such a widespread sexual network of respondents AIDS is likely to spread more widely if one member of the community is infected with AIDS.

\section{Conclusion}

The reproductive and sexual life of MSM community, both attitude knowledge and very vulnerable to HIV/AIDS.

\section{References}

1. Maleke K, Makhakhe N, Peters RP, Jobson G, De Swardt G, et al. (2017) HIV risk and prevention among men who have sex with men in rural South Africa. Afr J AIDS Res 16: 31-38.

2. Clifton S, Nardone A, Field N, Mercer CH, Tanton C, et al. (2016) HIV testing risk perception and behaviour in the British population. AIDS 30: 943-952.

3. Chen L, Pan X, Yang J, Xu Y, Wang H, et al. (2016) Analysis of related factors for HIV transmission among 263 pairs of male spouses with positive HIV antibodies in Zhejiang province. Zhonghua Yu Fang Yi Xue Za Zhi 50: 158-162.

4. Huang Q, Li Q, Li Y, Zeng G, Cui X, et al. (2015) Prevalence of HIV infection and syphilis, sexual behaviors and awareness of HIVIAIDS related knowledge among men who have sex with men in China: A Meta-analysis of data collected from 2010 to 2013. Zhonghua Liu Xing Bing Xue Za Zhi 36: 1297-1304.

5. Hu X, Chen F, Ding F, Lin X, Wang X, et al. (2015) Coverage of HIV related follow-up intervention and antiretroviral treatment and its correlation among HIV-positive men who have sex with men of 3 cities in China. Zhonghua Yu Fang Yi Xue Za Zhi 49: 945-949.

6. Lau JT, Mo PK, Gu J, Hao C, Lai CH (2016) Association of situational and environmental factors with last episode of unprotected anal intercourse among msm in Hong Kong: A case-crossover analysis. AIDS Educ Prev 28: 26-42.

7. Goedel WC, Halkitis PN, Greene RE, Hickson DA, Duncan DT (2015) HIV risk behaviors, perceptions and testing and preexposure prophylaxis (PrEP) awareness/use in grindr-using men who have sex with men in atlanta, Georgia. J Assoc Nurses AIDS Care 27: 133-142.

8. Liu Y, Osborn CY, Qian HZ, Yin L, Xiao D, et al. (2016) Barriers and facilitators of linkage to and engagement in HIV care among HIV-positive men who have sex with men in china: A qualitative study. AIDS Patient Care STDS 30: 70-77. 